\title{
Multisource data for seasonal variability analysis of cyanobacteria in a tropical inland aquatic environment
}

\author{
Rejane Ennes Cicerelli $i^{\mathrm{A}, \mathrm{B}, \mathrm{C}}$, Maria de Lourdes B. Trindade Galo
and Henrique Llacer Roig \\ A Universidade Estadual Paulista, Departamento de Cartografia, Rua Roberto Símonsen, \\ 305 - Centro Educacional, 19060-900, Presidente Prudente, São Paulo, Brazil. \\ ${ }^{\mathrm{B}}$ Universidade de Brasília, Instituto de Geociências, Campus Universitário Darcy Ribeiro \\ ICC - Ala Central, 71910-900, Brasília, Distrito Federal, Brazil \\ ${ }^{\mathrm{C} C o r r e s p o n d i n g ~ a u t h o r . ~ E m a i l ~ a d d r e s s: ~ r e j a n e i g @ u n b . b r ~}$
}

\begin{abstract}
Cyanobacterial blooms are related to eutrophic conditions that compromise the many uses of reservoirs. Thus, quick and effective methods for detecting the abundance of cyanobacteria in waterbodies are needed to complement conventional laboratory methods. In addition, inadequate control techniques that are applied at times of high cyanobacterial concentrations can cause the cells to lyse and release toxins into the water. In the present study we investigated the behaviour of cyanobacteria by determining phycocyanin and chlorophyll concentrations, using spectroradiometric and fluorometric techniques, in three field campaigns performed at the Nova Avanhandava Reservoir, Brazil. The sampling rate and favourable season for data collected had been determined previously by remote sensing analysis. Seasonal estimates of cyanobacteria were made because fluorometric sensors were able to record low concentrations, whereas the spectral analyses only detected phycocyanin at higher concentrations. Results of spectral analyses highlighted the subtle spectral characteristics indicating the presence of phycocyanin, even without a clear definition of the diagnostic features in the reflectance curve. Therefore, multiscale remote sensing complemented by fluorometric analysis and relevant environmental variables is an effective approach for monitoring cyanobacteria in Brazilian inland waters.
\end{abstract}

Additional keywords: fluorescence, phycocyanin, reflectance, tropical freshwater, water quality monitoring.

Received 20 July 2016, accepted 11 May 2017, published online 28 July 2017

\section{Introduction}

Detection and quantification of the biomass of cyanobacteria is critical to provide an early warning of bloom development (Tundisi et al. 2010; Li et al. 2015; Shi et al. 2015). Cyanobacteria can produce and release microcystins, a group of hepatotoxins. Microcystins produced by cyanobacterial cells are only released into the water if the cell wall is disrupted. Some algicides used to control cyanobacteria can promote cell lysis, and thus the release of toxins into the water (Sivonen and Jones 1999). To avoid this scenario prevention and control strategies should be performed. This only can be achieved with an integrated monitoring approach able to detect both increases in the density of cyanobacteria and the conditions of the aquatic environment is needed.

Cyanobacteria are present in many waterbodies worldwide, mostly at low concentrations. Under appropriate conditions (e.g. a large amount of nutrients, particularly nitrogen and phosphorus, temperatures above $25^{\circ} \mathrm{C}$ and adequate luminosity), the cyanobacteria can multiply rapidly and develop blooms (Coles and Jones 2000).

In Brazil, the importance of controlling the growth of cyanobacteria has led to the creation of a specific law by the
Ministry of Health (ordinance number 518/2004, which defines the minimum standards for drinking water) and the Ministry of Environment (resolution number 357/2005, which establishes water quality categories in Brazilian aquatic systems). However, this laws does not establish mechanisms to prevent cyanobacterial blooms. Therefore, in many cases actions to control the blooms are enacted after the environment is completely infested. To avoid this, the Ministry of Health published another law (ordinance number 2914/2011) that established new rules to control water quality for human consumption in cases of high cyanobacterial density. However, the costs associated with the sampling design are relatively high and the implementation process is complex.

In Brazil, São Paulo state has the highest economic growth and the largest metropolitan, industrial and agricultural areas, and is experiencing advanced eutrophication of water resources in some regions. Thus, the Environmental Company of the State of São Paulo (Companhia Ambiental do Estado de São Paulo) conducts quarterly sampling and manual counts of phytoplankton groups in 60 locations within the state of São Paulo. Despite the accuracy of the collection and analytical methods, the spatial and temporal coverage is not sufficient to provide a picture of the real 
conditions of the different waterbodies (Companhia Ambiental do Estado de São Paulo 2016).

Novo et al. $(2006,2013)$ have argued that remote sensing is an effective alternative for studies of Brazilian inland water systems. The possibility of acquisition of remote sensing data at different times of the year could provide information allowing inferences to be made about the status of aquatic environments based on the optical properties of their constituents.

Photosynthetic pigments can be detected in waterbodies on the basis of the specific optical properties of these pigments. The presence of the specific optically active pigment phycocyanin in cyanobacteria has allowed studies to be conducted using remote sensors, either by analysing the spectral signatures of phycocyanin associated with its spatial occurrence (Schalles et al. 1998; Seppälä et al. 2005; Li et al. 2015; Shi et al. 2015) or by using in vivo fluorescence data based on the specific absorption and emission spectra of phycocyanin pigments (Seppälä et al. 2005). Information about phycocyanin (and therefore cyanobacteria) based on its optical properties can be obtained by identifying diagnostic features in spectral reflectance curves using methods such as those reported by Goodin et al. (1993) and Chen (1992).

The aim of the present study was to investigate the seasonal behaviour of cyanobacteria in a run-off river reservoir experimental area using multisource data and multiscale remote sensing techniques. The methods included evaluation of the spectral and fluorometric responses of the phycocyanin pigment and its relationship with chlorophyll- $a(\mathrm{Chl}-a)$ and other physical variables in the aquatic environment. The study area was located along the Tietê River, São Paulo state, Brazil, in a section of the Nova Avanhandava Reservoir.

\section{Material and methods}

Experimental area and sampling design

The present study was performed in an experimental area located in the Nova Avanhandava Reservoir, in the middle course of the Tietê River (São Paulo, Brazil; Fig. 1 $a, b$ ). The reservoir flooding area is $210 \mathrm{~km}^{2}$, with a mean depth of $13 \mathrm{~m}$ and a mean annual flow rate of $688 \mathrm{~m}^{3} \mathrm{~s}^{-1}$ (AES Tietê - Power Generation Company, see http://www.aestiete.com.br/geracao/Paginas/nossasusinas.aspx, accessed 6 June 2017). The Nova Avanhandava Reservoir is the fifth reservoir in the Tietê River Cascade, which consists of six dams built between 1960 and 1990 for maximum exploitation of the hydropower potential as well as to provide water for many different uses by the population.

The first reservoir of the cascade (furthermost upstream) receives high nutrient loading from urban centres around the city of São Paulo and, despite the biodegradation and self-purification capacities of the river from the series of reservoirs, the system has suffered eutrophication effects in recent years (Dongpo et al. 2008). In addition, there is intensive agricultural use in the basin, in addition to the effects of urban waste and an industrial organic load. The industrial load results primarily from the sugarcane alcohol industry, which has increased the transport of nitrogen and phosphorus from the terrestrial to aquatic environment and results in a series of environmental effects (Rede Paulista de Educação Ambiental 2005).

A preliminary exploratory survey in the Nova Avanhandava Reservoir was conducted in February 2011. Phytoplankton activity was detected in the waterbody. In December 2011, this region was confirmed as the study area after a new exploratory survey. Biological analysis of the water aliquots collected in February 2011 by Utsumi et al. (2015) confirmed the dominance of cyanobacteria among the phytoplankton groups, primarily in the southern part of the reservoir.

The sampling design in the present study was based on temporal, spectral and spatial reflectance variability evaluated in multispectral images from the moderate-resolution imaging spectroradiometer (MODIS) and RapidEye spaceborne sensors. The temporal profile of the phytoplankton was evaluated to determine the most appropriate time of the year to obtain in situ measurements. This temporal profile was obtained by generating temporal signatures from MODIS images (MOD09A1) with a spatial resolution of $500 \mathrm{~m}$. Spectral Bands $3(459-479 \mathrm{~nm})$, $4(545-565 \mathrm{~nm})$ and $1(620-670 \mathrm{~nm})$ were used in the present analysis study they are considered appropriate for water studies (Novo et al. 2006). The temporal profile (Fig. 2) was generated from images acquired bimonthly from February 2009 to October 2011 , considering the average value of reflectance extracted from a square matrix of 9 pixels at the central point of the study area.

A RapidEye multispectral image acquired in February 2011 was used as a preliminary definition of the spatial sampling design. Spectral bands of green light (520-590 nm) and the red edge $(690-730 \mathrm{~nm})$ were used to generate a ratio image (red edge divided by green). The RapidEye red edge band is considered an effective data source for providing data of phytoplankton distribution with high spatial resolution (Wen et al. 2014). The positions of the sampling stations were defined as those regions with greater radiometric variability and were determined by dividing the sampling area into a 45 -cell grid. For each cell, the ratio image average and s.d. were calculated. Cells that had similar statistical parameters were merged until there were 30 complete points (Fig. 1c). After merging similar cells, a single random point was positioned in each merged group of cells.

The sampling design followed the pattern of temporal, spectral and spatial reflectance variability, but the original sample size of each field campaign was different due to weather conditions (e.g. rain or the presence of clouds) or instrumental and logistical issues, primarily in September 2012. At every georeferenced sampling site, spectroradiometric and fluorometric data were acquired to estimate the concentrations of Chl- $a$ and phycocyanin, in addition to measurements of certain limnological and environmental variables to characterise the collection points. Furthermore, water samples were collected in 10-mL chambers as part of the February 2012 field campaign and preserved in Lugol's solution at a ratio of $1: 100$ for subsequent identification of phytoplankton groups and total density counts. To quantify the density of phytoplankton, the Utermöhl method of counting individuals was used, with results expressed as the number of individuals per millilitre. An 'individual' was considered as being a filament, a tricome, a colony, a coenobium or a cell (for unicellular individuals; Uhelinger 1964). There is no consensus about the best quantification method for the calculation of phytoplankton diversity, but the number of individuals has been used for a long time, including in recent literature (Figueredo and Giani 2001). 


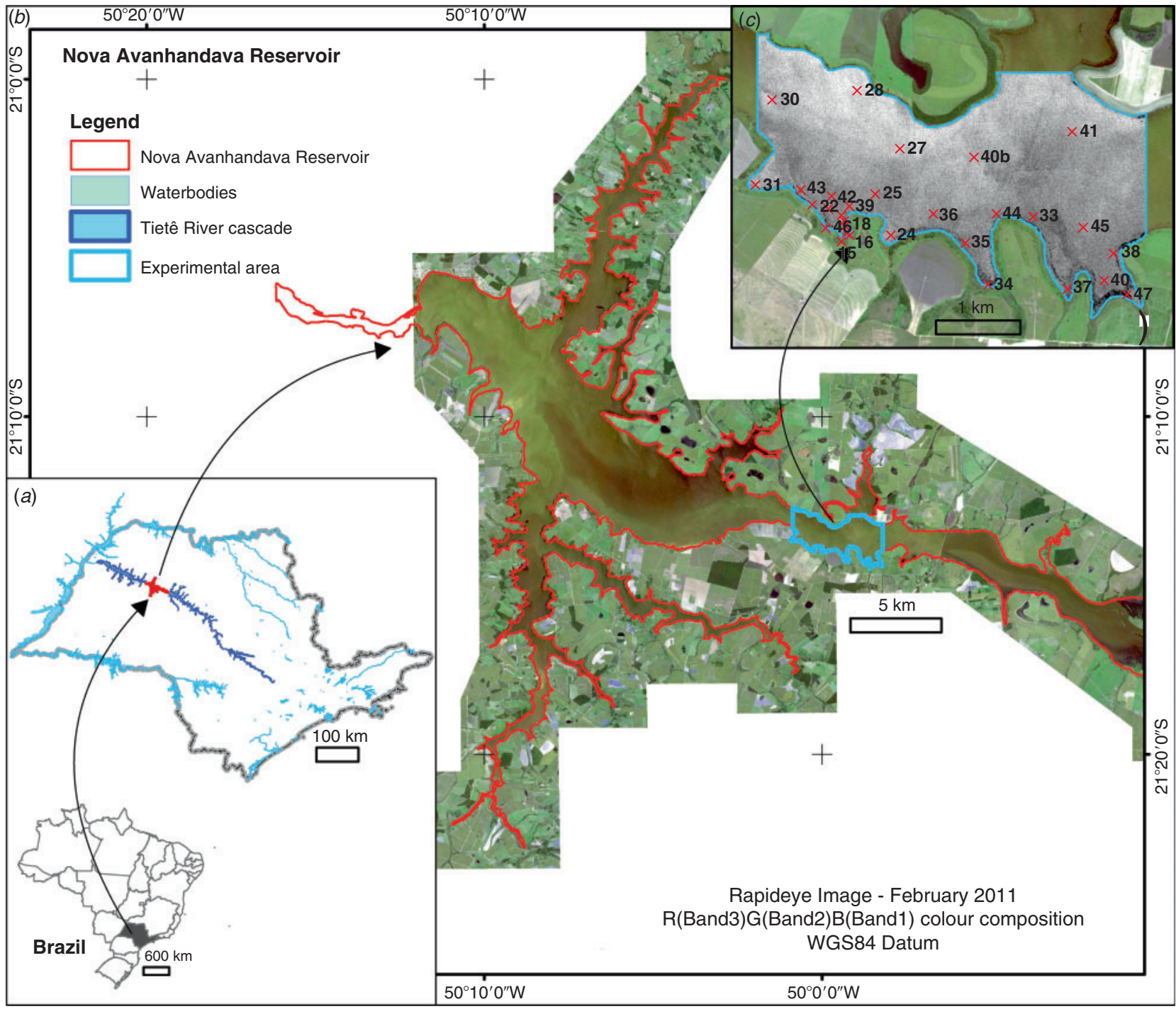

Fig. 1. (a) Location of the Nova Avanhandava Reservoir in Tietê River cascade (São Paulo, Brazil). (b) Colour composition of RapidEye multispectral image showing intensive agricultural use surrounding the reservoir. The study area is highlighted in light blue. (c) Ratio image generated from RapidEye bands (red edge divided by green) with the location of sample stations (points labelled with red cross and black numbers) shown in the experimental area.

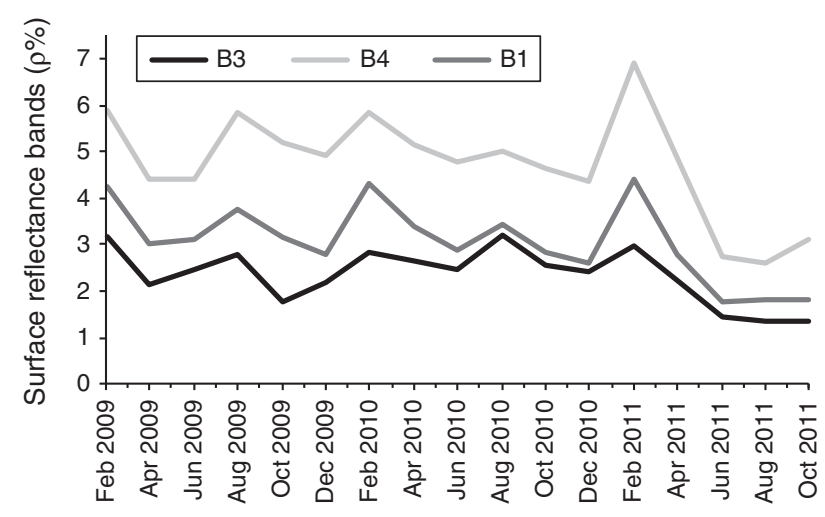

Fig. 2. Reflectance profile in MODIS) Spectral Bands 3 (459-479 $\mathrm{nm})$, $4(545-565 \mathrm{~nm})$ and $1(620-670 \mathrm{~nm})$ generated for the period February 2009-October 2011.
Limnological values (water temperature, dissolved oxygen, turbidity (Alfakit Company, model AT, see https://alfakit.ind.br/, accessed 6 June 2017) and water transparency (Secchi depth)) were obtained during each field campaign using instruments in the field. Weather data (minimum and maximum air temperature, wind speed and direction, monthly accumulated rainfall, number of rainy days and moisture) were also obtained, from the Instituto Nacional de Meteorologia (INMET) weather station (A735; $\left.-21^{\circ} 05^{\prime} 8.43^{\prime \prime} \mathrm{S},-49^{\circ} 55^{\prime} 13,4^{\prime \prime} \mathrm{W}\right)$, located $40 \mathrm{~km}$ from the reservoir.

In vivo fluorescence: data collection and processing

Fluorometric sensors were used to obtain the concentration of phytoplankton pigments, measured at a depth of $30 \mathrm{~cm}$. The phycocyanin concentration was measured using a UniLux Submersible Fluorometer device (Chelsea Technologies Group, 
see https://www.chelsea.co.uk/, accessed 6 June 2017) and calibrated by the supplier (Chelsea Technologies Ltd 2010). The UniLux device recorded the in vivo fluorescence of phycocyanin pigment within a dynamic range of $0-100 \mu \mathrm{g} \mathrm{L}^{-1}$, with a detection limit of $0.01 \mu \mathrm{g} \mathrm{L}^{-1}$.

Chl- $a$ fluorescence values were obtained using a $10 \mathrm{AU}$ Field Fluorometer (Turner Designs, see http://www.turnerdesigns.com/), which provides relative values of in vivo fluorescence. Thus, in vivo fluorescence values were calibrated using Chl- $a$ concentrations acquired from laboratory extraction using the spectrophotometric method of Goterman (1978). Figure 3 shows the calibration curves relating in vivo fluorescence values to absolute concentrations of Chl- $a$ for each field survey.

To analyse the seasonal aspect of spatial dispersion of phytoplankton pigments in the study area, as well as the representativeness of the sampling design used in each field survey, concentrations of phycocyanin and Chl- $a$ were used to produce thematic maps describing the spatial distribution of Chl- $a$ and phycocyanin concentrations through Thiessen polygons. In these maps, the size and shape of the polygons depend on the density and spatial distribution of the sample elements. Colours are related to the concentrations of Chl- $a$ and phycocyanin acquired in each field survey.

\section{In situ hyperspectral data}

Hemispherical-conical reflectance factor (HCRF) values were obtained in field measurements using a ASD FieldSpec HandHeld model, UV/VNIR spectroradiometer (for wavelengths 325-1075 nm; Panalytical Company, see https://www.asdi.com/ products-and-services/fieldspec-spectroradiometers) operating in the spectral range $375-1075 \mathrm{~nm}$ with 512 channels and a 1.6-nm nominal spectral resolution. HCRF is the ratio of the radiance of the sample $\left(\mathrm{L}_{\mathrm{a}} ; \lambda\right)$ and the radiance of a Lambertian reference surface $\left(\mathrm{L}_{\mathrm{r}} ; \lambda\right)$, measured under the same conditions of illumination and observation. This reflectance factor accounts for large instantaneous fields of view (IFOV). IFOV values were acquired using sensor measurements performed under ambient sky illumination. In this case, the assumption of a zero interval of the solid angle for the measured reflected radiance beam does not hold true (Schaepman-Strub et al. 2006).

Spectral analytical methods (e.g. derivative analysis and continuum removal technique) were used to extract spectral information associated with scattering and absorption features related to the phycocyanin pigment and to consequently evaluate the occurrence of cyanobacteria in the study area.

In hyperspectral remote sensing, derivative analysis was used to discriminate the effects and quantify the concentration of sediments and chlorophyll in the water (Chen 1992; Goodin et al. 1993). The mathematical basis for the spectral derivative is established by the change of reflectance related to the wavelength ( $\lambda$; Chen 1992). Graphically, it is represented by the slope of the tangent at each point of the curve; thus, the derivative shows the points where there are sudden changes in spectral response. The derivatives can be estimated by finite approximation, as shown by Tsai and Philpot (1998).

Continuum removal allows normalisation of the spectral reflectance to compare individual absorption features from a
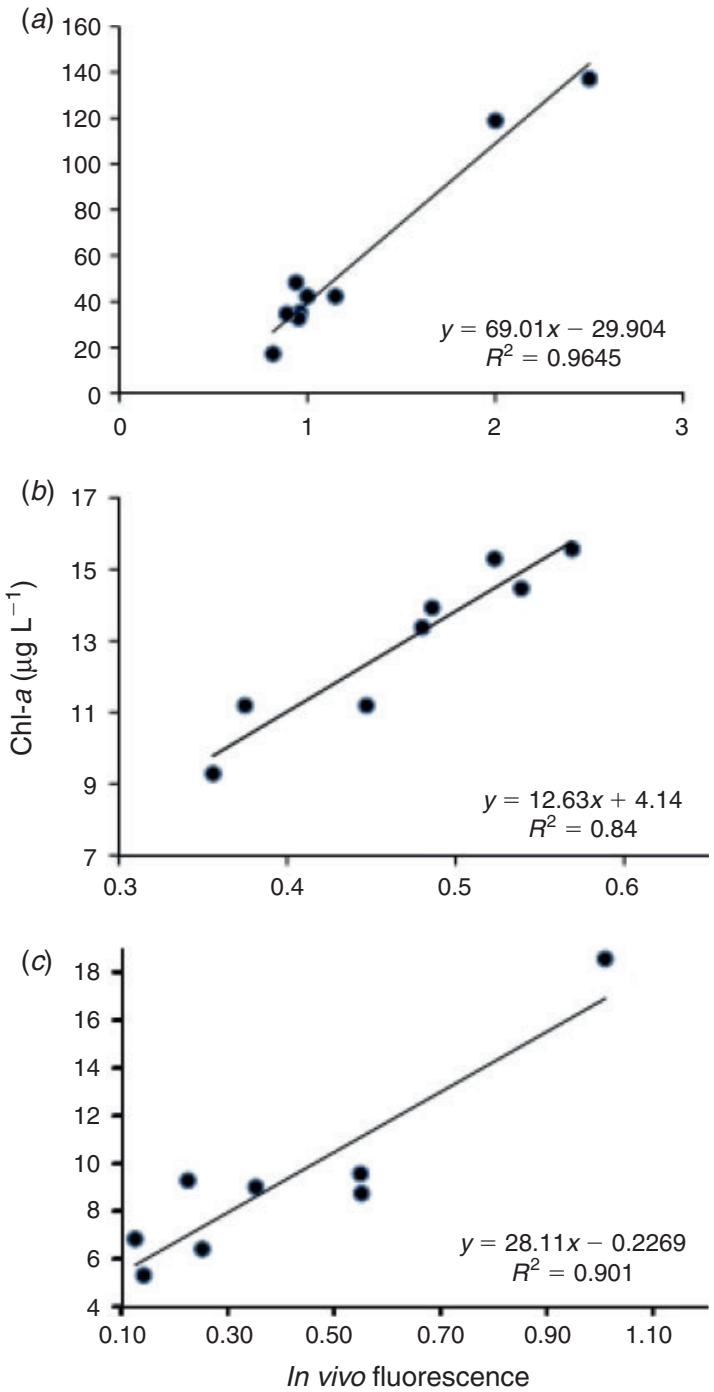

Fig. 3. Linear regression equations used to estimate chlorophyll (Chl)- $a$ concentrations by fluorometry in ( $a$ ) February 2012 (nine points), (b) March 2012 (eight points) and (c) September 2012 (eight points).

common baseline. The continuum spectrum is described mathematically by the line equation: the linear and angular coefficients set the upper and lower limits for each absorption feature (Clark and Roush 1984; Mutanga et al. 2004). An absorption feature resulting from continuum removal contains associated parameters, such as depth, area and width. The spectral interval used to detect the phycocyanin pigment in water was between 610 and $645 \mathrm{~nm}$, with a central wavelength of $627 \mathrm{~nm}$.

The spectral parameters obtained were correlated with phycocyanin concentration. For the definition of significant Pearson correlation coefficients as a function of the number of sample elements, Fisher's exact test of independence was used with the level of significance set at $P<0.01$ and an acceptance threshold of $99 \%$ (Armitage et al. 2002). Thus, significant correlations $(r)$ for the first, second and third field surveys should be greater than $0.42,0.44$ and 0.56 respectively. 


\section{Results and discussion}

\section{Phytoplankton activity in the study area}

Figure 2 shows temporal profiles of phytoplankton behaviour obtained from Spectral Bands 3 (459-479 nm), 4 (545-565 nm) and $1(620-670 \mathrm{~nm})$ of the MODIS image (MOD09A1). In the three spectral bands evaluated, the reflectance values were higher in February and lower in October. Therefore, on the basis of this distinct phytoplankton behaviour, available resources and logistics, field campaigns were conducted in February, March and September 2012.

Table 1. Statistical indicators of the chlorophyll (Chl)- $a$ and phycocyanin concentrations obtained from in situ collection of water samples

\begin{tabular}{llll}
\hline & February 2012 & March 2012 & September 2012 \\
\hline Phycocyanin $\left(\mu \mathrm{g} \mathrm{L}^{-1}\right)$ & & & \\
Maximum & 50.24 & 4.71 & 2.32 \\
Minimum & 1.47 & 0.46 & 0.23 \\
Mean \pm s.d. & $7.12 \pm 10.05$ & $2.58 \pm 0.99$ & $1.39 \pm 0.71$ \\
Chl- $a(\mu \mathrm{g} \mathrm{L}-1)$ & & & \\
Maximum & 150.96 & 16.04 & 24.35 \\
Minimum & 8.93 & 8.59 & 5.32 \\
Mean \pm s.d. & $47.54 \pm 34.21$ & $12.31 \pm 2.26$ & $11.86 \pm 4.32$ \\
Number of samples & 29 & 30 & 18 \\
\hline
\end{tabular}

Table 2. Phytoplankton groups identified in the February 2012 field survey

\begin{tabular}{lc}
\hline Phytoplankton group & Individuals $\mathrm{mL}^{-1}(\%)$ \\
\hline Bacillariophyceae & $115(6)$ \\
Chlorophyceae & - \\
Cryptophyceae & $229(16)$ \\
Crysophyceae & - \\
Cyanophyceae & $1418(76)$ \\
Dinophyceae & $23(1)$ \\
Euglenophyceae & - \\
Zygnemaphyceae & $23(1)$ \\
Total & $1871(100)$ \\
\hline
\end{tabular}

February was the month of greater photosynthetic activity (Fig. 2), as indicated by MODIS temporal analyses, so the ratio image generated from red edge and green RapidEye spectral bands of February 2011 was used to distribute the sample elements in the experiment. Other sampling stations were set in the areas that showed greater radiometric variability, such as the region near the south shoreline (Fig. 1c).

Analysis of phytoplankton activity in the experimental area was based on Chl- $a$ and phycocyanin concentrations determined using fluorescence methods. Brazilian legislation (resolution number 357/2005) establishes a concentration limit up to $30 \mu \mathrm{g} \mathrm{L}^{-1}$ Chl- $a$ in multiple-use reservoirs. For phycocyanin, the maximum value was based on the results reported by Brient et al. (2008), who showed that cyanobacteria become dominant in an environment with phycocyanin concentrations $>10 \mu \mathrm{g} \mathrm{L}^{-1}$.

These Chl- $a$ and phycocyanin thresholds were used as reference values for statistical analyses of phytoplankton occurrence in the experimental area. In February 2012, the Chl- $a$ and phycocyanin concentrations were close to values registered in aquatic environments dominated by cyanobacteria, as reported by the field survey. The concentrations obtained in surveys conducted in other seasons of the year were below the reference values, indicating that the waterbodies were only slightly affected (Table 1).

During the February 2012 field survey, the phycocyanin and Chl- $a$ concentrations had the highest s.d. values, demonstrating greater variability in terms of their spatial distribution.

The density of phytoplankton individuals (separated by groups) was estimated in water samples collected in February 2012 (Table 2) as individuals per millilitre and as percentages, only to verify whether there were cyanobacteria in the reservoir. The ratio of occurrence shows the dominance of the specific cyanobacteria group Cyanophyceae, with a proportion $>70 \%$ in terms of individuals. Moreover, among the cyanobacteria genera identified in the samples, the dominance of Microcystis is disturbing because these cyanobacteria are able to release toxins into the aquatic environment.

The effect of weather conditions (Table 3 ) on the occurrence of cyanobacteria, as determined on the basis of phycocyanin concentrations, is consistent with findings reported in the

Table 3. Data on environmental and limnological variables collected during each field campaign NTU, Nephelometric turbidity unit

\begin{tabular}{lccc}
\hline & February 2012 & March 2012 & September 2012 \\
\hline Air temperature $\left({ }^{\circ} \mathrm{C}\right)$ & & & 23 \\
$\quad$ Minimum & 22 & 24 & 19 \\
$\quad$ Maximum & 24 & 2.5 & 24 \\
Wind speed $\left(\mathrm{m} \mathrm{s}^{-1}\right)$ & 2.5 & South-westerly & North-easterly \\
Wind direction & North-westerly & 80 & 70 \\
Accumulated monthly rainfall (mm) & 80 & 8 & 5 \\
Number of months in which rain fell & 8 & 62 & 40 \\
Humidity $(\%)$ & 70 & 29.8 & 26.8 \\
Water temperature $\left({ }^{\circ} \mathrm{C}\right)$ & 29 & 3.5 & 2.7 \\
Water transparency $(\mathrm{m})$ & 2.6 & 7.1 & 9.8 \\
Dissolved oxygen $\left(\mathrm{mg} \mathrm{L}^{-1}\right)$ & 5.9 & 9.0 & 2.6 \\
Turbidity (NTU) & 23.7 & & \\
& & & \\
\end{tabular}




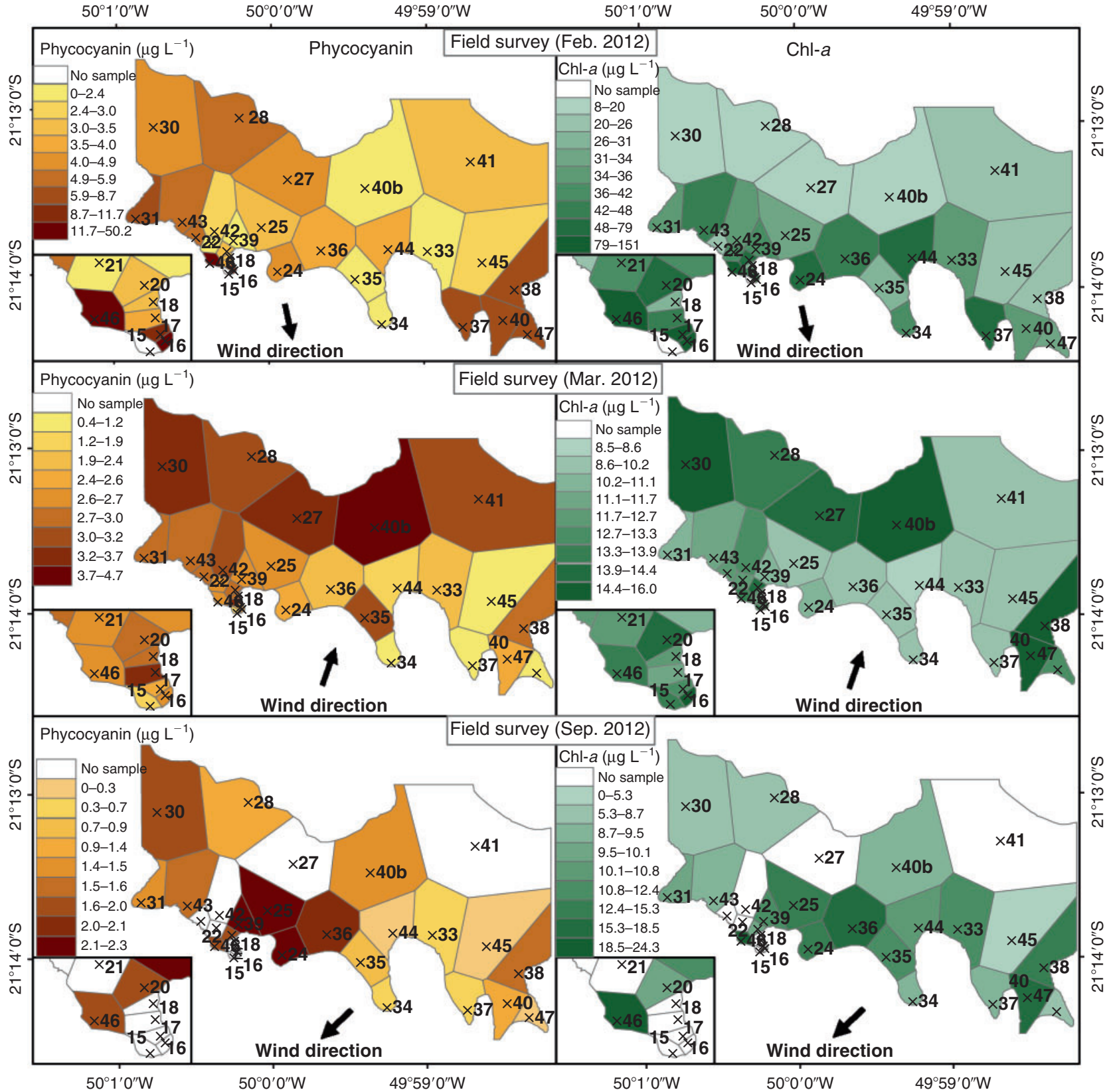

Fig. 4. Quantitative spatial distribution per area of phycocyanin (left-hand panels) and chlorophyll (Chl)- $a$ (right-hand panels) concentrations based on the in situ surveys conducted in February, March and September 2012. The arrows indicate the direction of the winds on the dates of the field surveys.

literature for freshwater ecosystems at tropical and subtropical latitudes (Tundisi et al. 2010). The results of the present study suggest, as do the results of Tundisi et al. (2010), that in February relatively high air and water temperatures, wet days, light wind speed and several rainfall events introduced nutrients into the environment, creating a favourable environment for the proliferation of cyanobacteria. March was characterised by the highest precipitation to the start the autumn period and low concentrations of Chl- $a$ and phycocyanin (Tables 1,3). Tundisi et al. (2010) explained this period as alternating between stability and mixing that creates the so-called 'moderate vertical mixing associated with a previous cold front'. In September, a cold front just before the field survey (associated with medium winds and low temperatures) may have caused mixing events, significantly reducing the population of cyanobacteria, as evidenced by the phycocyanin and Chl- $a$ concentrations in Table 1.

Values of other limnological variables (Table 3) indicate that turbidity increased with Chl- $a$ and phycocyanin concentrations, and with decreasing water transparency. Turbidity had an inverse and exponential relationship with water transparency, and a hyperbolic relationship with Chl- $a$ (Schalles et al. 1998).

Thematic maps (Fig. 4) were created to illustrate seasonal and spatial variations in Chl- $a$ and phycocyanin concentrations together with wind direction. In February 2012, many samples, 
(a)
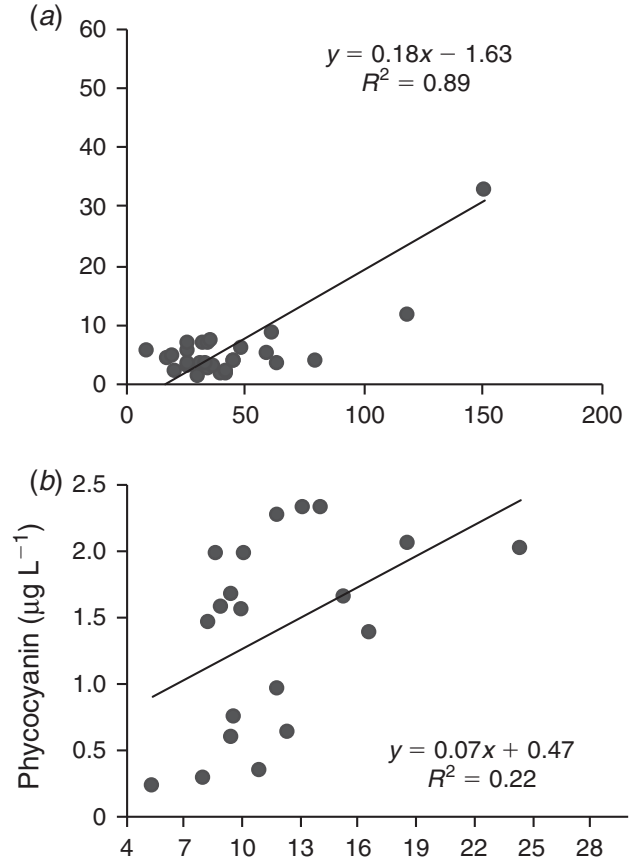

(c)

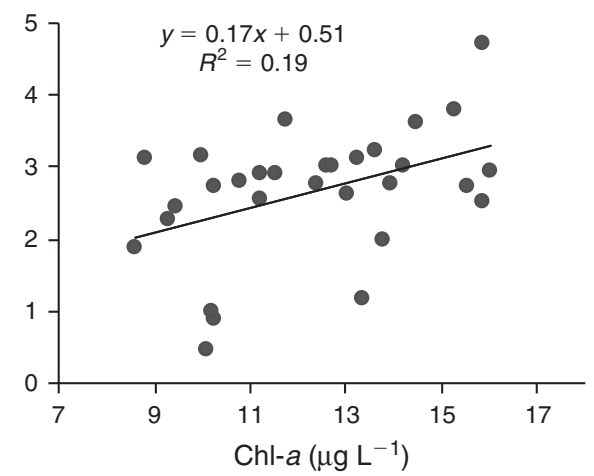

Fig. 5. Correlation between phycocyanin and chlorophyll (Chl)- $a$ concentrations based on in situ measurements conducted in (a) February 2012, (b) March 2012 and (c) September 2012.

primarily from the southern part of the experimental area, had the highest concentrations of phytoplankton pigments, coinciding with wind direction (top panels, Fig. 4).

Maps containing data collected in March 2012 (middle panels, Fig. 4) coincided with the effect of winds in defining the highest concentrations of these pigments, found at this time in the northern part of the experimental area, even though the wind velocity was low. This field survey was characterised by strong rain events near the field survey. We suggest that the effects of mixing were greater in the southern (shallower) than northern (deeper) part of the reservoir.

In the field survey of September 2012, the highest concentrations of phycocyanin and Chl- $a$ (bottom panels, Fig. 4) were again seen in the southern part of the experimental area, despite the lower number of data points. During this period, winds were of medium intensity $\left(4.0 \mathrm{~m} \mathrm{~s}^{-1}\right)$, and ranged from northeast to south-west (Table 3). Despite the similarity in phycocyanin and Chl- $a$ spatial variability for each field survey, there is low correlation between these variables when the concentration is low (March 2012 and September 2012; Fig. 5). A fundamental problem of fluorescence measurements of algae is that molecular events are responsible for the different types of fluorescence quenching, and this can lead to artefacts and misinterpretations (Büchel and Wilhelm 1993).

\section{Feasibility of hyperspectral analysis in detecting phycocyanin}

Smoothing filters were used to reduce the effect of random noise in the reflectance factor curves. In spectra obtained during the February 2012 field campaign, a five-point mean smoothing filter was adopted (Tsai and Philpot 1998), whereas for March and September 2012 a Fourier transformation filtering method was used to remove the high-frequency components (Bracewell 1989).

The smoothed spectral curves defined in the wavelength range from 400 to $900 \mathrm{~nm}$ are shown in Fig. 6, with vertical dashed lines representing the spectral locations of the diagnostic features of absorption and scattering of phycocyanin and Chl- $a$, as in Richardson (1996) and Kirk (1994), among others.

The highest reflectance factor values were obtained in February 2012 (Fig. 6a) and the spectral features are clearly associated with phycocyanin and Chl- $a$ pigments. In the March and September 2012 field surveys, the behaviour of the curves indicates reduced variability due to low concentrations of phytoplankton pigments.

Maximum reflectance values in the green region (between 550 and $570 \mathrm{~nm}$ ) caused by the presence of Chl- $a$ are visible in the reflectance curves, as well as in the absorption features in the red region (i.e. absorption maximum near $671 \mathrm{~nm}$ ) and the peak reflectance in the near-infrared region (i.e. absorption minimum near 700 nm; Fig. 6a). Furthermore, a representative peak is observed at $750 \mathrm{~nm}$, which can be attributed to scattering caused by assembly of phytoplankton cells or by total suspended solids (Dekker 1993; Kirk 1994).

Some phycocyanin spectral curves show a subtle absorption feature near $620 \mathrm{~nm}$ and a scattering peak near $650 \mathrm{~nm}$, as reported in the literature for aquatic environments containing cyanobacteria (Dekker 1993; Le et al. 2011). In the February 2012 field survey, these features were more pronounced (Fig. 6a).

Figure 7 shows curves resulting from the application of the second derivative for each field survey. The subtle phycocyanin features of the absorption and scattering wavelengths (620 and $650 \mathrm{~nm}$ respectively) become more obvious in the second derivatives because these features have positive values for absorption and negative values for scattering (dashed lines). All field surveys featured curves exhibiting this behaviour, but the magnitude of the second derivative was higher and the dispersion was lower for the February 2012 survey, when the highest concentrations of phycocyanin were obtained.

For continuum removal, the range containing the main phycocyanin absorption feature (between 610 and $645 \mathrm{~nm}$ ) was adopted. Table 4 gives correlation levels among the in vivo fluorescence phycocyanin concentrations and the continuum removal parameters (height, width, asymmetry and area) for each survey campaign. Area and height values had the highest correlation with phycocyanin concentration. This result 

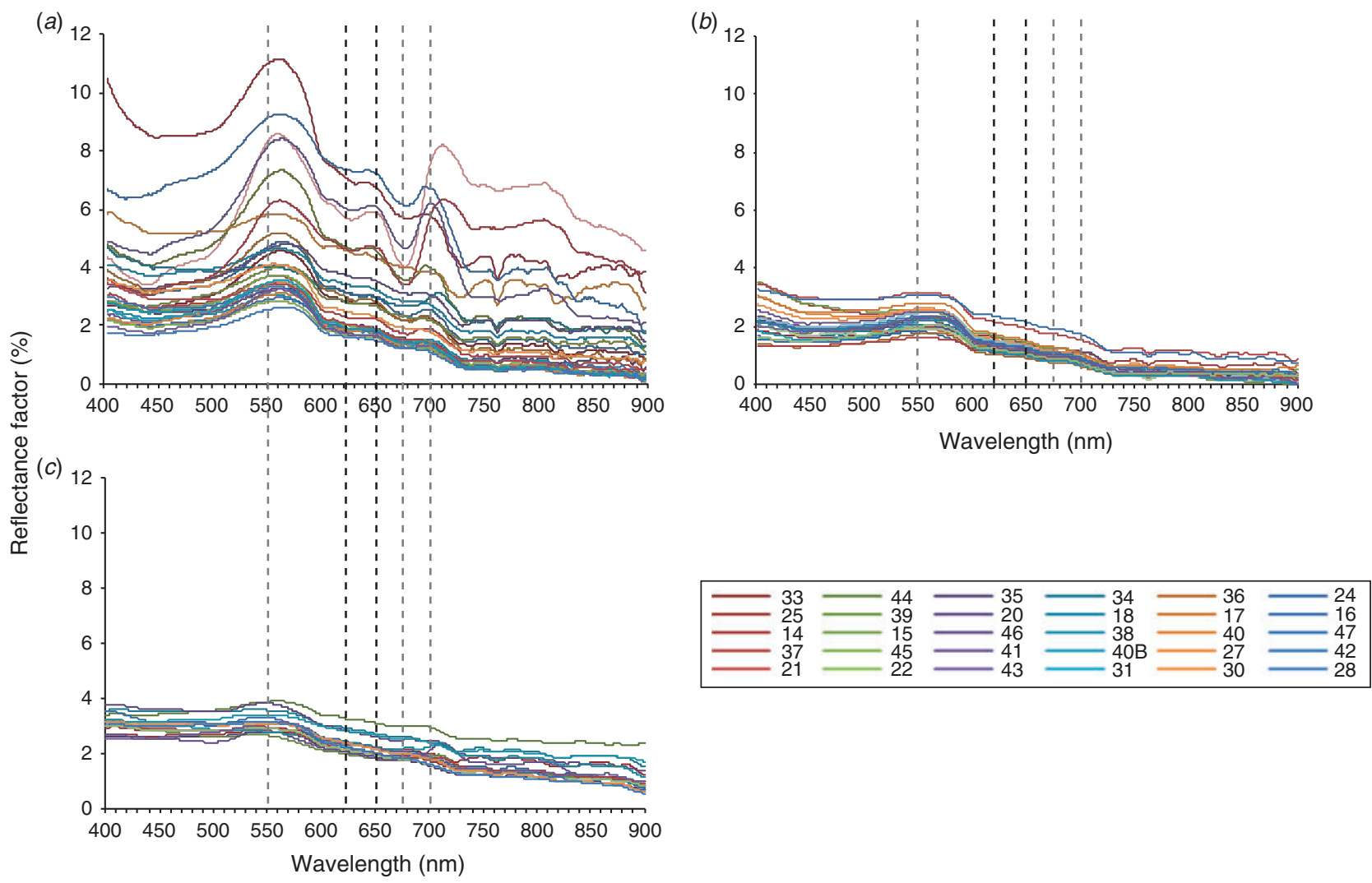

Fig. 6. Smoothed spectral curves obtained in (a) February 2012 (30 points), (b) March 2012 (27 points) and (c) September 2012 (18 points). The black dashed lines indicate the position of the diagnostic features of phycocyanin $(620$ and $650 \mathrm{~nm})$ and the grey dashed lines indicate the position of the diagnostic features of chlorophyll- $a(550,675$ and $700 \mathrm{~nm})$.

confirms the effect of phycocyanin absorption near $620 \mathrm{~nm}(\mathrm{Li}$ et al. 2015). The highest correlation between area and phycocyanin concentrations was obtained for February 2012. A similar result for correlation was observed for the March 2012 survey, with lower concentrations of phycocyanin.

The efficiency of the reflectance curves and the methods of spectral analysis in assessing the occurrence of phycocyanin in the study area are expressed by the correlation between the most representative variables and the pigment concentration measured by in vivo fluorescence (Table 5). Phycocyanin was correlated with the original spectral curves at 620 and $650 \mathrm{~nm}$, with the second derivatives at 620 and $650 \mathrm{~nm}$ and with the area and height parameters of the continuum removal for each field survey. The relationship between phycocyanin and Chl- $a$ concentrations, obtained by fluorometry, for each field campaign is shown in Fig. 3.

The correlation values in Table 5 indicate that the highest correlations were obtained between higher concentrations of phycocyanin, measured by in vivo fluorescence, and the second derivative. However, even these indicators were not efficient when phycocyanin concentrations in the waterbody were very low. Cyanobacteria can move vertically in the water column and the vertical distribution of cyanobacteria may have an effect on the remote sensing signal measured, hampering the collection of data (Kutser et al. 2008). Furthermore, the fluorescence efficiency of pigments is dependent on their history of exposure to light when measured in vivo, leading to diurnal variations, even in vertical profiles (Smith et al. 1981). This process can change the in vivo fluorescence measured in the field, considering the capacity of light penetration in relation to phytoplankton concentration.

Indeed, correlation values obtained for the February 2012 field survey (highest concentration of phycocyanin) showed that the spectral response curves expressed by reflectance and the derived spectral metrics can be indicators of the presence of phycocyanin, and therefore cyanobacteria, in waterbodies. The average concentration of phycocyanin for February (7.12 $\left.\mu \mathrm{g} \mathrm{L}^{-1}\right)$ corresponds to a value below the critical level (which is $>10 \mu \mathrm{g} \mathrm{L}^{-1}$; as in Brient et al. 2008). However, even without the risk of dominance by cyanobacteria in the study area, spectral analysis can be an effective tool for monitoring water quality and for preventive diagnosis of an increase in these organisms in the aquatic environment. Thus, spectral data may be useful for characterising cyanobacteria blooms despite the adverse effects of low concentrations of phycocyanin pigment on the spectral response.

Fluorescence data may provide more useful information in the presence of low phycocyanin and Chl- $a$ concentrations, even though the fluorescent signal is affected by: (1) environmental light and nutrient conditions; (2) the presence of other optically active components (OAC), such as dissolved organic matter (CDOM), Chl- $b$, Chl- $c_{1}$ and Chl- $c_{2}$; and (3) the composition of 


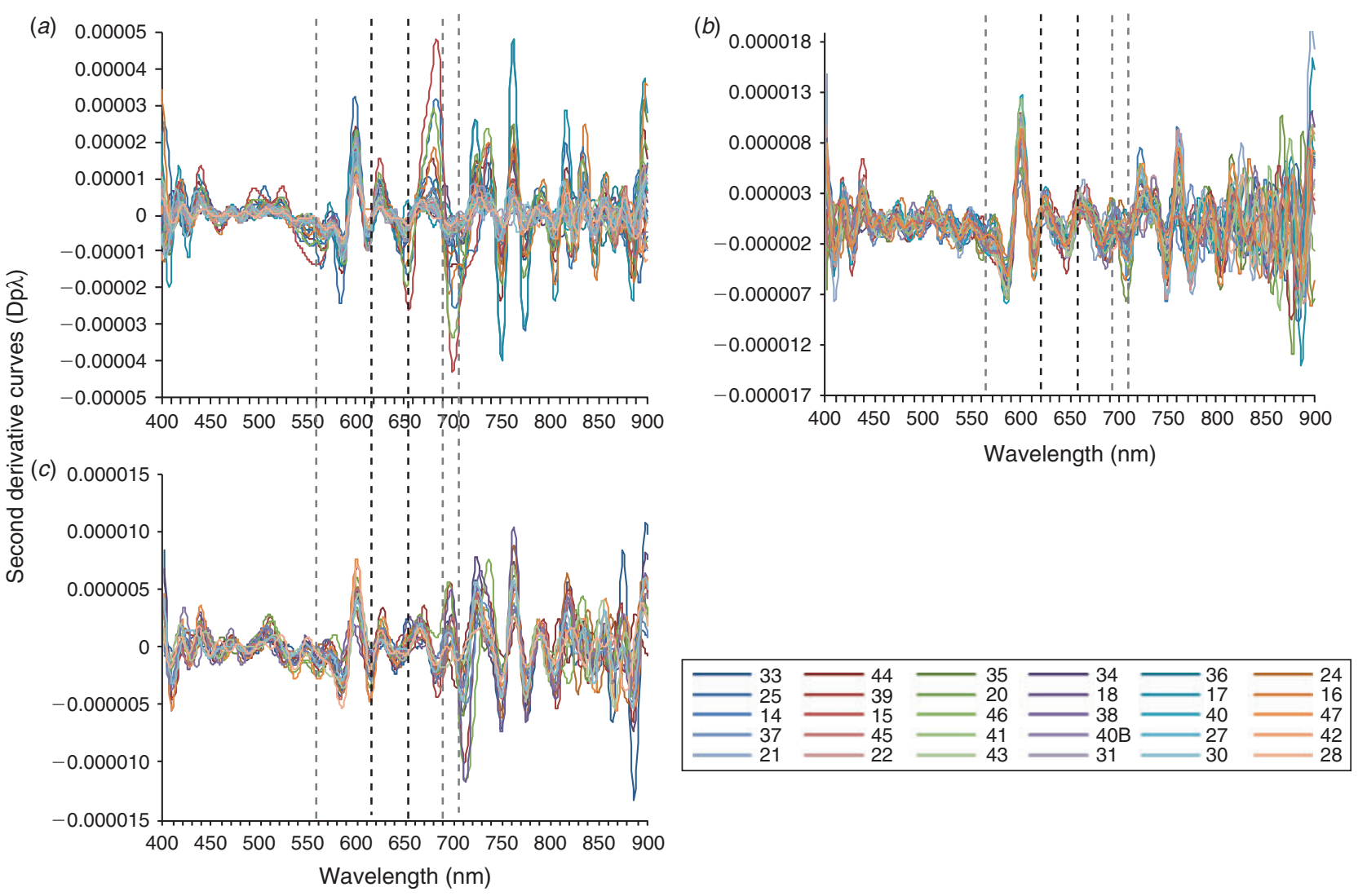

Fig. 7. Second derivative of the reflectance curves related to field surveys performed in (a) February 2012, (b) March 2012 and (c) September 2012. The dashed lines indicate the position of the diagnostic features of phycocyanin $(620$ and $650 \mathrm{~nm})$ and chlorophyll- $a(550,675 \mathrm{and} 700 \mathrm{~nm})$. Dp $\lambda$, second derivative curves.

Table 4. Correlation coefficients between in vivo fluorescence concentrations of phycocyanin and continuum removal parameters for the absorption feature for the interval $610-645 \mathrm{~nm}$

\begin{tabular}{lccc}
\hline Parameter & February 2012 & March 2012 & September 2012 \\
\hline Height & 0.57 & 0.39 & 0.02 \\
Width & 0.25 & 0.29 & 0.10 \\
Asymmetry & -0.26 & -0.26 & 0.19 \\
Area & 0.64 & 0.43 & 0.08 \\
\hline
\end{tabular}

the phytoplankton species (Le et al. 2011; Belzile et al. 2004, Kiefer 1973).

In short, an approach that incorporates multiple data sources and various analytical tools for the effective monitoring of multipurpose reservoirs at potential risk of cyanobacterial blooms is needed.

Initially, a sampling network should be properly designed in space and time using, for example, orbital multispectral images with strategic spectral bands for discrimination of phytoplanktonic pigments in fast revisit time (high temporal resolution). These series of images may be integrated with environmental data (e.g. temperature), and finally indicate areas favourable for bloom development (according to wind direction and speed). Moreover, remote sensing is a promising tool for the diagnosis of features associated with the occurrence of phycocyanin in reflectance curves, either by indirect analysis, by monitoring concentrations of Chl- $a$ or by inversion of analytical models.

\section{Conclusions}

The feasibility of assessing the spatial and temporal behaviour of cyanobacteria in tropical fresh water based on the spectral and fluorescent properties of the phycocyanin pigment was confirmed in the present study. This study presents an alternative to the monitoring of water quality given the difficulty of acquiring a significant number of samples in large waterbodies to detect cyanobacteria blooms using traditional limnology sampling.

Phycocyanin and Chl- $a$ concentrations, as well as factors defining conditions for both cyanobacterial proliferation and dispersal in aquatic environments, were evaluated in three field campaigns. The analysis of the spatial dispersion of the phycocyanin pigment showed that the largest concentration of this pigment coincided with wind direction. Similar results were found for Chl- $a$, indicating that the dispersion of phytoplankton is generally influenced by wind direction.

During the tropical summer, phycocyanin and Chl- $a$ concentrations exhibited significant spatial variation, with some of the sampling points reaching alarming levels in February, when the aquatic environment exhibited eutrophic behaviour. 
Table 5. Correlation between in vivo fluorescence concentrations of phycocyanin and the information extracted from spectral reflectance curves for each field campaign Chl- $a$, chlorophyll- $a$

\begin{tabular}{lccr}
\hline & February 2012 & March 2012 & September 2012 \\
\hline Reflectance factor & & & -0.11 \\
At $620 \mathrm{~nm}$ & 0.50 & -0.25 & -0.10 \\
At $650 \mathrm{~nm}$ & 0.56 & -0.25 & 0.55 \\
Second derivative value & & 0.40 & -0.50 \\
At $620 \mathrm{~nm}$ & 0.80 & -0.20 & 0.10 \\
At $650 \mathrm{~nm}$ & 0.96 & 0.43 & 0.05 \\
Area parameter (continuum removal): $610-645 \mathrm{~nm}$ & 0.64 & 0.39 & 0.47 \\
Height parameter (continuum removal): $610-645 \mathrm{~nm}$ & 0.58 & 0.44 & \\
Phycocyanin and Chl- $a$ concentrations & 0.79 & & \\
\hline
\end{tabular}

Irregular spatial distribution and seasonal concentrations of phytoplankton and cyanobacteria were confirmed, regardless of their concentration. These variations support the requirement of a higher number of sample elements and a better spatial distribution of programs to monitor water quality of Brazilian inland waters.

The use of multisensor data with regard to the fluorescent and spectral properties of phycocyanin was adequate to analyse the seasonal behaviour and spatial distribution of cyanobacteria. The fluorometric sensors recorded low signal levels, enabling estimates of even low concentrations of pigments, whereas the spectral response for detecting phycocyanin is constrained by its low strength at low concentrations. However, hyperspectral remote sensing is an effective approach for monitoring phytoplankton, and the results of the present study showed that even without defining clear diagnostic features in the reflectance curve (as with Chl- $a$ ), the use of techniques to analyse spectral curves can highlight the specific subtle spectral characteristics of phycocyanin.

Regarding the methods of extracting information from spectral curves, the values of the second derivative at wavelengths of 620 and $650 \mathrm{~nm}$ resulted in high correlation coefficients with phycocyanin concentrations ( 0.8 and 0.96 respectively) for data acquired in February 2012.

Monitoring the growth and dispersion of cyanobacteria in aquatic environments is fundamental to preventing the occurrence of blooms and the emergency control measures related to them. These measures may cause cell lysis and release microcystin into the water. From this perspective, the present study demonstrated the use of a monitoring approach based on the spectral and fluorescent behaviour of the phycocyanin pigment, integrating multiscale and multisensory remote sensing data. The collection of consistent data at different times of the year showed the spatial and seasonal variability in cyanobacteria and the possibility for the development of rapid and reliable methods of monitoring cyanobacteria blooms.

\section{Conflicts of interest}

The authors declare that they have no conflicts of interest.

\section{Acknowledgements}

The authors thank Coordenadoria de Aperfeiçoamento de Pessoal de Nível Superior (CAPES), Universidade Estadual Paulista (UNESP), Fundação de
Estudos e Pesquisas Agrícolas e Florestais (FEPAF) and Fundação para o Desenvolvimento da UNESP (FUNDUNESP) for financial and technical support with the field surveys. The authors also thank Programa de PósGraduação em Ciências Cartográficas (PPGCC) for training support.

\section{References}

Armitage, P., Berry, P. J., and Matthews, J. N. S. (2002). 'Statistical Methods in Medical Research', 4th edn. (Blackwell Publishing: Oxford, UK.)

Belzile, C., Vicent, W. F., Williams, C. H., Hawes, I., James, M. R., Kumagai, M., and Roesler, C. S. (2004). Relationships between spectral optical properties and optically active substances in a clear oligotrophic lake. Water Resources Research 40, WR003090. doi:10.1029/ 2004WR003090

Bracewell, R. N. (1989). The Fourier transform. Scientific American 260, 86-95. doi:10.1038/SCIENTIFICAMERICAN0689-86

Brient, L., Lengronne, M., Bertrand, E., Rolland, D., Sipel, A., Steinmann, D., Baudin, I., Legeas, M., Le Rouzic, B., and Bormans, B. (2008). A phycocyanin probe as a tool for monitoring cyanobacteria in freshwater bodies. Journal of Environmental Monitoring 10, 248-255. doi:10.1039/ B714238B

Büchel, C., and Wilhelm, C. (1993). In vivo analysis of slow chlorophyll fluorescence induction kinetics in algae: progress, problems and perspectives. Photochemistry and Photobiology 58, 137-148. doi:10.1111/ J.1751-1097.1993.TB04915.X

Chelsea Technologies Ltd (2010). 'Trilux Calibration Procedure 2125-080CP.' (Chelsea Technologies: West Molesey, UK.)

Chen, Z. (1992). Derivative reflectance spectroscopy to estimate suspended sediment concentration. Remote Sensing of Environment 40, 67-77. doi:10.1016/0034-4257(92)90127-6

Clark, R. N., and Roush, T. L. (1984). Reflectance spectroscopy: quantitative analysis techniques for remote sensing applications. Journal of Geophysical Research 89, 6329-6340. doi:10.1029/ JB089IB07P06329

Coles, J. F., and Jones, R. C. (2000). Effect of temperature on photosynthesis-light response and growth of four phytoplankton species isolated from a tidal freshwater river. Journal of Phycology 36, 7-16. doi:10.1046/J.1529-8817.2000.98219.X

Companhia Ambiental do Estado de São Paulo (2016). Relatório de qualidade das águas superficiais do Estado de São Paulo, 2015. (CETESB: São Paulo, Brazil.)

Dekker, A. G. (1993). Detection of optical water quality parameters for eutrophic waters by high resolution remote sensing. Ph.D. Thesis, Vrije Universiteit, Amsterdam, Netherlands.

Dongpo, S., Ruili, L., Youngjun, S., and Jun, Y. (2008). Impact of hydroelectric projects on river environment: analysis of water quality changes in Ningxia Reach of Yellow River. Water Science and Engineering 2, 66-75. 
Figueredo, C. C., and Giani, A. (2001). Seasonal variation in the diversity and species richness of phytoplankton in a tropical eutrophic reservoir. Hydrobiologia 445, 165-174. doi:10.1023/A:1017513731393

Goodin, D. G., Han, L., Fraser, R. N., Rundquist, D. C., Stebbins, W. A., and Schalles, J. F. (1993). Analysis of suspended solids in water using remotely sensed high resolution derivate spectra. Photogrammetric Engineering and Remote Sensing 59, 505-510.

Goterman, H. L. (1978). 'Methods for Physical and Chemical Analysis of Fresh Waters.' (Limnological Institute: Oxford, UK.)

Kiefer, D. A. (1973). Chlorophyll- $a$ fluorescence in marine centric diatoms: responses of chloroplasts to light and nutrient stress. Marine Biology 23, 39-46. doi:10.1007/BF00394110

Kirk, J. T. O. (1994). 'Light and Photosynthesis in Aquatic Ecosystems.' (Cambridge University Press: Cambridge, UK.)

Kutser, T., Metsamaa, L., and Dekker, A. G. (2008). Influence of the vertical distribution of cyanobacteria in the water column on the remote sensing signal. Estuarine, Coastal and Shelf Science 78, 649-654. doi:10.1016/ J.ECSS.2008.02.024

Le, C., Li, Y., Zha, Y., Wang, Q., Zhang, H., and Yin, B. (2011). Remote sensing of phycocyanin pigment in highly turbid inland waters in Lake Taihu, China. International Journal of Remote Sensing 32, 8253-8269. doi: $10.1080 / 01431161.2010 .533210$

Li, L., Lin, L., and Song, K. (2015). Remote sensing of freshwater cyanobacteria: an extended IOP inversion model of inland waters (IIMIW) for partitioning absorption coefficient and estimating phycocyanin. Remote Sensing of Environment 157, 9-23. doi:10.1016/J.RSE. 2014.06.009

Mutanga, O., Skidmore, A. K., and Prins, H. H. T. (2004). Predicting in situ pasture quality in the Kruger National Park, South Africa, using continuum-removed absorption features. Remote Sensing of Environment 89, 393-408. doi:10.1016/J.RSE.2003.11.001

Novo, E. M. L. M., Barbosa, C. C. F., Freitas, R. F., Shimabukuro, Y. E., Melack, J. M., and Filho, W. O. (2006). Seasonal changes in chlorophyll distributions in Amazon floodplain lakes derived from MODIS images. Limnology 7, 153-161. doi:10.1007/S10201-006-0179-8

Novo, E. M. L. M., Londe, L. R., Barbosa, C. C. F., Araujo, C. A. S., and Rennó, C. D. (2013). Proposal for a remote sensing trophic state index based upon Thematic Mapper/Landsat images. Revista Ambiente \& Água 8(3), 65-82. doi:10.4136/AMBI-AGUA.1229

Rede Paulista de Educação Ambiental (2005). Orientação para educação ambiental nas bacias hidrográficas do Estado de São Paulo: origem e caminhos. In 'Origem e caminhos da REPEA-Rede Paulista de Educação Ambiental'. (Eds M. P. Borba, P. Otero, and C. H. R. Pinheiro.) pp. 81-126. (Imprensa Oficial do Estado de São Paulo: São Paulo, Brazil.)
Richardson, L. L. (1996). Remote sensing of algal bloom dynamics; new research fuses remote sensing of aquatic ecosystems with algal accessory pigment analysis. Bioscience 46, 492-501. doi:10.2307/1312927

Schaepman-Strub, G., Schaepman, M. E., Painter, T. H., Dangel, S., and Martonchik, L. V. (2006). Reflectance quantities in optical remote sensing - definitions and case studies. Remote Sensing of Environment 103, 27-42. doi:10.1016/J.RSE.2006.03.002

Schalles, J. F., Gitelson, A. A., Yacobi, Y. Z., and Kroenke, A. E. (1998). Estimation of chlorophyll $a$ from time series measurements of high spectral resolution reflectance in an eutrophic lake. Journal of Phycology 34, 383-390. doi:10.1046/J.1529-8817.1998.340383.X

Seppälä, J., Ylöstalob, P., and Kuosac, H. (2005). Spectral absorption and fluorescence characteristics of phytoplankton in different size fractions across a salinity gradient in the Baltic Sea. International Journal of Remote Sensing 26, 387-414. doi:10.1080/01431160410001723682

Shi, K., Zhang, Y., Li, Y., Li, L., Lv, H., and Liu, X. (2015). Remote estimation of cyanobacteria-dominance in inland waters. Water Research 68, 217-226. doi:10.1016/J.WATRES.2014.10.019

Sivonen, K., and Jones, G. (1999). Cyanobacterial toxins. In 'Toxic Cyanobacteria in Water: a Guide to their Public Health Consequences, Monitoring and Management'. (Eds I. Chorus and J. Bartram.) pp. 290-307. (E \& FN Spon: London, UK.)

Smith, R. C., Baker, K. S., and Dustan, P. (1981). 'Fluorometric Techniques for the Measurement of Oceanic Chlorophyll in the Support of Remote Sensing.' (Scripps Institution of Oceanography: San Diego, CA, USA.)

Tsai, F., and Philpot, W. (1998). Derivative analyses of hyperspectral data. Remote Sensing of Environment 66, 41-51. doi:10.1016/S0034-4257 (98)00032-7

Tundisi, J. G., Matsumura-Tundisi, T., Pereira, K. C., Luzia, A. P., Passerini, M. D., Chiba, W. A. C., Morais, M. A., and Sebastien, N. Y. (2010). Cold fronts and reservoir limnology: an integrated approach towards the ecological dynamics of freshwater ecosystems. Brazilian Journal of Biology 70, 815-824. doi:10.1590/S1519-69842010000400012

Uhelinger, V. (1964). Étude statistique des méthodes de dénobrement planctonique. Archives des Sciences 17, 121-123.

Utsumi, A. G., Galo, M. L. B. T., and Tachibana, V. M. (2015). Mapeamento de cianobactérias por meio da fluorescência da ficocianina e de análise geoestatística. Revista Brasileira de Engenharia Agrícola e Ambiental 19(3), 273-279. doi:10.1590/1807-1929/AGRIAMBI.V19N3P273-279

Wen, X., Zhou, Z., Chen, B., Li, Z., and Tang, X. (2014). Research on the features of chlorophyll-a derived from Rapideye and EOS/MODIS data in Chaohu Lake. IOP Conference Series: Earth and Environmental Science 17, 1-5. doi:10.1088/1755-1315/17/1/012111 